\title{
The Canadian STOP-PAIN project - Part 1: Who are the patients on the waitlists of multidisciplinary pain treatment facilities?

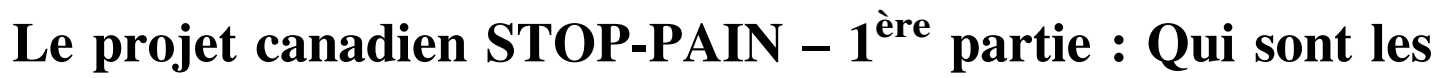 patients sur les listes d'attente pour les établissements pluridisciplinaires de traitement de la douleur?
}

\author{
Manon Choinière, PhD • Dominique Dion, MD • Philip Peng, MBBS • \\ Robert Banner, MD • Pamela M. Barton, MD • Aline Boulanger, MD • \\ Alexander J. Clark, MD • Allan S. Gordon, MD • Denise N. Guerriere, PhD • \\ Marie-Claude Guertin, PhD • Howard M. Intrater, MD • Sandra M. Lefort, PhD • \\ Mary E. Lynch, MD • Dwight E. Moulin, MD • May Ong-Lam, MD • \\ Mélanie Racine, $\mathbf{P h D}(\mathrm{c}) \cdot$ Saifee Rashiq, MB · Yoram Shir, MD • \\ Paul Taenzer, PhD · Mark Ware, MBBS
}

Received: 5 November 2009/Accepted: 15 March 2010/Published online: 15 April 2010

(c) Canadian Anesthesiologists' Society 2010

\begin{abstract}
Purpose The Canadian STOP-PAIN Project assessed the human and economic burden of chronic pain in individuals
\end{abstract}

This article is accompanied by an editorial. Please see Can J Anesth 2010; 57(6)

This portion of the Canadian STOP-PAIN PROJECT was led by Manon Choinière, Dominique Dion and Philip Peng. The other coinvestigators were by alphabetical order: Robert Banner, Pamela M. Barton, Aline Boulanger, Alexander J. Clark, Allan S. Gordon, Denise N. Guerriere, Marie-Claude Guertin, Howard M. Intrater, Sandra M. Lefort, Mary E. Lynch, Dwight E. Moulin, May Ong-Lam, Mélanie Racine, Saifee Rashiq, Yoram Shir, Paul Taenzer, Mark Ware.

Electronic supplementary material The online version of this article (doi:10.1007/s12630-010-9305-5) contains supplementary material, which is available to authorized users.

M. Choinière, $\mathrm{PhD}(\square)$

Centre de recherche du Centre hospitalier de l'Université de Montréal (CRCHUM), Pavillon Masson, Bureau 8-211, 3850, St-Urbain Street, Montreal, QC H2W 1T7, Canada e-mail: manon.choiniere.chum@ssss.gouv.qc.ca

M. Choinière, $\mathrm{PhD}$

Montreal Heart Institute, Montréal, QC, Canada

D. Dion, MD

Dept of Family Medicine, Faculty of Medicine, University

of Montreal, Montréal, QC, Canada

P. Peng, MBBS · A. S. Gordon, MD

Wasser Pain Management Clinic, Mount Sinai Hospital,

Toronto, ON, Canada on waitlists of Multidisciplinary Pain Treatment Facilities (MPTF). This article presents the patients' bio-psycho-social profile.

Methods A sample of 728 patients was recruited from waitlists of eight university-affiliated MPTFs across Canada. Subjects completed validated questionnaires to: 1) assess the characteristics and impact of their pain; and 2) evaluate their emotional functioning and quality of life (QoL). Follow-up questionnaires were completed by a subgroup of 271 patients three months later.

Results Close to 2/3 of the participants reported severe pain $(\geq 7 / 10)$ that interfered substantially with various aspects of their daily living and QoL. Severe or extremely severe levels of depression were common (50.0\%) along with suicidal ideation (34.6\%). Patients aged $>60 \mathrm{yr}$ were

R. Banner, MD · S. Rashiq, MB

Multidisciplinary Chronic Pain Centre, University of Alberta, Edmonton, AB, Canada

P. M. Barton, MD - P. Taenzer, $\mathrm{PhD}$

Chronic Pain Centre of the Calgary Health Region Centre,

Calgary, AB, Canada

A. Boulanger, MD

Pain Clinic of the Centre hospitalier de l'Université de Montréal, Montréal, QC, Canada

A. J. Clark, MD - M. E. Lynch, MD

Pain Management Unit, Queen Elizabeth II Health Sciences

Centre, Halifax, NS, Canada 
twice as likely to experience severe pain $(\geq 7 / 10)$ as their younger counterparts $(P=0.002)$. Patients with frequent sleep problems were more at risk of reporting severe pain $(P \leq 0.003)$. Intense pain was also associated with a greater tendency to catastrophize $(P<0.0001)$ severe depressive symptoms $(P=0.003)$ and higher anger levels $(P=0.016)$. Small but statistically significant changes in pain intensity and emotional distress were observed over a three-month wait time (all $P<0.05)$.

Conclusion This study highlights the severe impairment that patients experience waiting for treatment in MPTFs. Knowing that current facilities cannot meet the clinical demand, it is clear that effective prevention/treatment strategies are needed earlier in primary and secondary care settings to minimize suffering and chronicity.

\section{Résumé}

Objectif Le projet canadien STOP-PAIN a évalué le fardeau humain et économique que représentait la douleur chronique des personnes se trouvant sur les listes d'attente des établissements pluridisciplinaires de traitement de la douleur (MPTF - Multidisciplinary Pain Treatment Facilities). Cet article présente le profil bio-psycho-social de ces patients.

Méthode Un échantillon de 728 patients a été recruté à partir des listes d'attente de huit MPTF affiliés à des universités partout au Canada. Les participants ont rempli des questionnaires validés afin de: 1) évaluer les

D. N. Guerriere, $\mathrm{PhD}$

Dept of Health Policy, Management, and Evaluation, University of Toronto, Toronto, ON, Canada

M.-C. Guertin, $\mathrm{PhD}$

Montreal Heart Institute Coordinating Centre, Montréal, QC, Canada

H. M. Intrater, MD

Health Sciences Centre Pain Clinic, University of Manitoba, Winnipeg, MB, Canada

\section{S. M. Lefort, PhD}

School of Nursing, Memorial University of Newfoundland,

St John's, NL, Canada

D. E. Moulin, MD

London Health Sciences Centre, London, ON, Canada

M. Ong-Lam, MD

St. Paul's Hospital Pain Centre, Vancouver, BC, Canada

M. Racine, $\mathrm{PhD}(\mathrm{c})$

Dept of Psychology, Université du Québec à Montréal,

Montréal, QC, Canada

Y. Shir, MD · M. Ware, MBBS

Pain Centre of the McGill University Health Centre, Montréal,

QC, Canada caractéristiques et l'impact de leur douleur; et 2) évaluer leur fonctionnement émotionnel et leur qualité de vie $(Q d V)$. Des questionnaires de suivi ont été remplis trois mois plus tard par un sous-groupe de 271 patients.

Résultats Près de 2/3 des participants ont fait état d'une douleur grave $(\geq 7 / 10)$ qui entravait considérablement différents aspects de leur vie quotidienne et de leur QdV. Des niveaux graves ou extrêmement graves de dépression étaient fréquents (50,0\%), tout comme les idées suicidaires $(34,6 \%)$. Les patients âgés de $>60$ ans couraient un risque deux fois plus élevé de ressentir des douleurs graves $(\geq 7 / 10)$ que les participants plus jeunes $(P=0,002)$. Les patients ayant souvent des problèmes de sommeil couraient un risque plus élevé de faire état de douleur grave $(P \leq 0,003)$. Une douleur intense était également associée à une tendance plus prononcée à la dramatisation $(P<0,0001)$, à des symptômes de dépression grave $(P=0,003)$ et à des niveaux plus élevés de colère $(P=0,016)$. Des changements petits mais significatifs au niveau de l'intensité de la douleur et de la détresse émotionnelle ont été observés sur une période d'attente de trois mois (tous $P<0,05$ ).

Conclusion Cette étude met en évidence le handicap grave que les patients ressentent pendant qu'ils attendent d'être traités dans un MPTF. Sachant que les établissements actuels ne peuvent répondre à la demande clinique, il est clair que des stratégies de prévention et de traitement efficaces sont nécessaires plus tôt dans les cadres de soins primaires et secondaires afin de minimiser la souffrance et la chronicité.

Chronic pain affects approximately one in five Canadian adults $^{1,2, \mathrm{~A}}$ and the human and economic burden associated with this health care problem is believed to be enormous. Despite decades of research, chronic pain continues to be largely undertreated or mistreated, resulting in a large number of patients going from doctor to doctor seeking pain relief. Multidisciplinary pain treatment is recognized as the optimal paradigm ${ }^{3, \mathrm{~B}}$ for a good proportion of these patients, but access is restricted due to the limited number of facilities and long waiting lists. ${ }^{4,5}$ A recent Canadian survey identified six months as the median wait time for a first appointment in public multidisciplinary pain treatment facilities (MPTFs). This means that $50 \%$ of patients have to wait six months or more (with a range of up to five years)

\footnotetext{
A Statistics Canada. Health Indicators. Ottawa, Canada: Statistics Canada; 2002. Report No.: Catalogue no.82-221-XIE, Volume 2002, No. 1.

B Multidisciplinary Pain Programs for Chronic Pain: Evidence from systematic reviews (HTA 30), Ospina M, Harstall C, (2003).
} 
for access to appropriate pain treatment, with $30 \%$ of clinics reporting waitlists of more than one year and vast areas of the country remaining unserviced. ${ }^{4}$ What is the economic burden of their pain? What is the impact of having to wait months for treatment of chronic pain? Since we lack reliable information on these issues at the present time, there is a clear requirement for research into this patient population to better understand their specific needs. Also, economic data on chronic pain are very important when determining and allocating treatment resources.

The objectives of the Canadian STOP-PAIN Project were two-fold: 1) to portray the bio-psycho-social profile of patients on MPTF waitlists; and 2) to evaluate the economic burden of their pain. The results of this study are reported in two consecutive papers. The present paper (Part 1) describes the characteristics and impact of patients' pain, their psychological status and health-related quality of life (QoL). The effect of a three-month wait time on patients' pain severity and emotional distress was also examined. The companion article (Part 2) provides the results of the economic analysis.

\section{Methods}

Study design and selection of participants

A cross-sectional design was used to study patients on the waitlists of eight large university-affiliated MPTFs located in seven provinces across Canada. A subgroup of participants was randomly selected for a prospective follow up of a three-month period. Adult patients were eligible to participate in the study if they were referred to a MPTF for the first time due to chronic non-cancer pain lasting for at least six months. Patients were excluded if: 1) their medical condition required immediate evaluation and treatment, e.g., acute complex regional pain syndrome; 2) they were unable to complete an English or French questionnaire due to a language barrier; and 3) they were unable to give informed consent because of cognitive disorders. This study, which was conducted from November 2004 to October 2007, was approved by the Research Ethics Boards (REB) of all participating centres (Montreal Heart Institute REB being the leading institution).

Initial assessment

The medical directors of each MPTF mailed a letter to all patients on their waitlist inviting them to enrol in the present study. The invitation letter with a response card was sent to all new patients in the order they were referred to the MPTF during the study period. Patients who accepted the invitation were invited to provide written informed consent and to complete a self-administered questionnaire to be returned by mail. This questionnaire (Appendix 1, available as Electronic Supplementary Material) included standardized validated scales designed to collect the following information: 1) pain characteristics, including intensity (0-10 numerical rating scale [NRS] ${ }^{6}$ and impact on daily living (interference items of the modified Brief Pain Inventory [BPI] $)^{7,8}$ 2) sleep problems (four items selected from the Chronic Pain Sleep Inventory [CPSI] $)^{9}$ 3) psychological distress, including depression (Beck Depression Inventory [BDI-I]), ${ }^{10}$ anxiety (NRS) and anger levels (NRS); 4) tendency to catastrophize in the face of pain (Pain Catastrophizing Scale [PCS]); ${ }^{11,12} 5$ ) healthrelated QoL (SF-36v2); ${ }^{13}$ and 6) socio-demographics. Also, all study participants were invited to participate in a structured face-to-face or telephone interview with trained research nurses to obtain the following additional information: 1) cause of pain; 2) current and past medication used for pain; 3) current and past non-pharmacological pain treatments; 4) type of health care professionals consulted for pain; and 5) current health problems other than pain. A copy of the structured interview protocol is available as Electronic Supplementary Material (Appendix 2).

All the nurses who were involved in the STOP-PAIN Project were experienced research nurses who completed one-day training prior to the start of the study. Each nurse was provided with the STOP-PAIN Research Nurse Handbook that detailed the procedures related to all study phases.

\section{Follow-up assessment}

Using a computer-generated set of random numbers, a subgroup of patients ( $70 \%$ of the initial sample) was randomly selected from the initial sample for follow-up assessment by a trained research nurse. In this subgroup of patients, prior pain-related use of health care resources and pain costs were quantified prospectively using the Ambulatory and Home Care Record $(\mathrm{AHCR})^{14}$ over a threemonth period (see details of the procedure in a companion article, The Canadian STOP-PAIN Project - Part 2, by Guerriere et al. published in this issue of the Journal). At the end of this period, patients' pain intensity (NRS), depression (BDI-I), anxiety and anger levels (NRS) were re-assessed to evaluate the impact of a three-month wait time on their condition.

\section{Data analysis}

The results are expressed as means \pm standard deviations, medians, or percentages. Multiple logistic regression analysis was performed to identify variables that distinguished patients with severe pain (pain intensity at its usual level in the past seven days $\geq 7 / 10$ ) from those who had pain of 
lesser intensity $(<7 / 10)$. Only variables with a $P$ value of $<0.25$ in univariate logistic regression analysis were considered as potential predictors in the final regression model. Independent Student's $t$ tests were used for group comparisons. Paired Student's $t$ tests served to compare the data collected during the initial and follow-up interviews.

\section{Results}

As shown in Figure 1, 40.4\% of the 3,343 patients who were sent a letter of invitation consented to participate in the study. A total of 728 patients entered the study (corrected response rate: $24.9 \%$ ) after excluding patients who did not meet the selection criteria and those who either were not reached or did not complete the initial interview. Participants were equally distributed among the eight study sites (Table 1). The patients' mean age was $50.8 \pm 12.6$ (range: $20-88$ ) yr, $60.6 \%$ were female, and close to half of the patients were unable to work due to illness or disability (Table 2).

Pain characteristics, psychological distress and health-related QoL

Ninety percent of the patients described their pain as continuous. As illustrated in Table 3, pain duration varied from 0.5 to $55 \mathrm{yr}$ (median 5.0), and $61.0 \%$ of the patients rated their average pain in the past week as severe $(\geq 7 /$ 10). ${ }^{15,16}$ More than half of the patients stated that their pain interfered importantly $(\geq 7 / 10)$ with various aspects of their daily living, including normal work, walking ability, and recreational and social activities (Table 3). More than $60 \%$ of the patients disclosed major sleep problems
Fig. 1 Diagram of participant flow and response rate. The denominator of the corrected response rate was calculated by subtracting the number of excluded subjects from the total number of those who were invited to participate

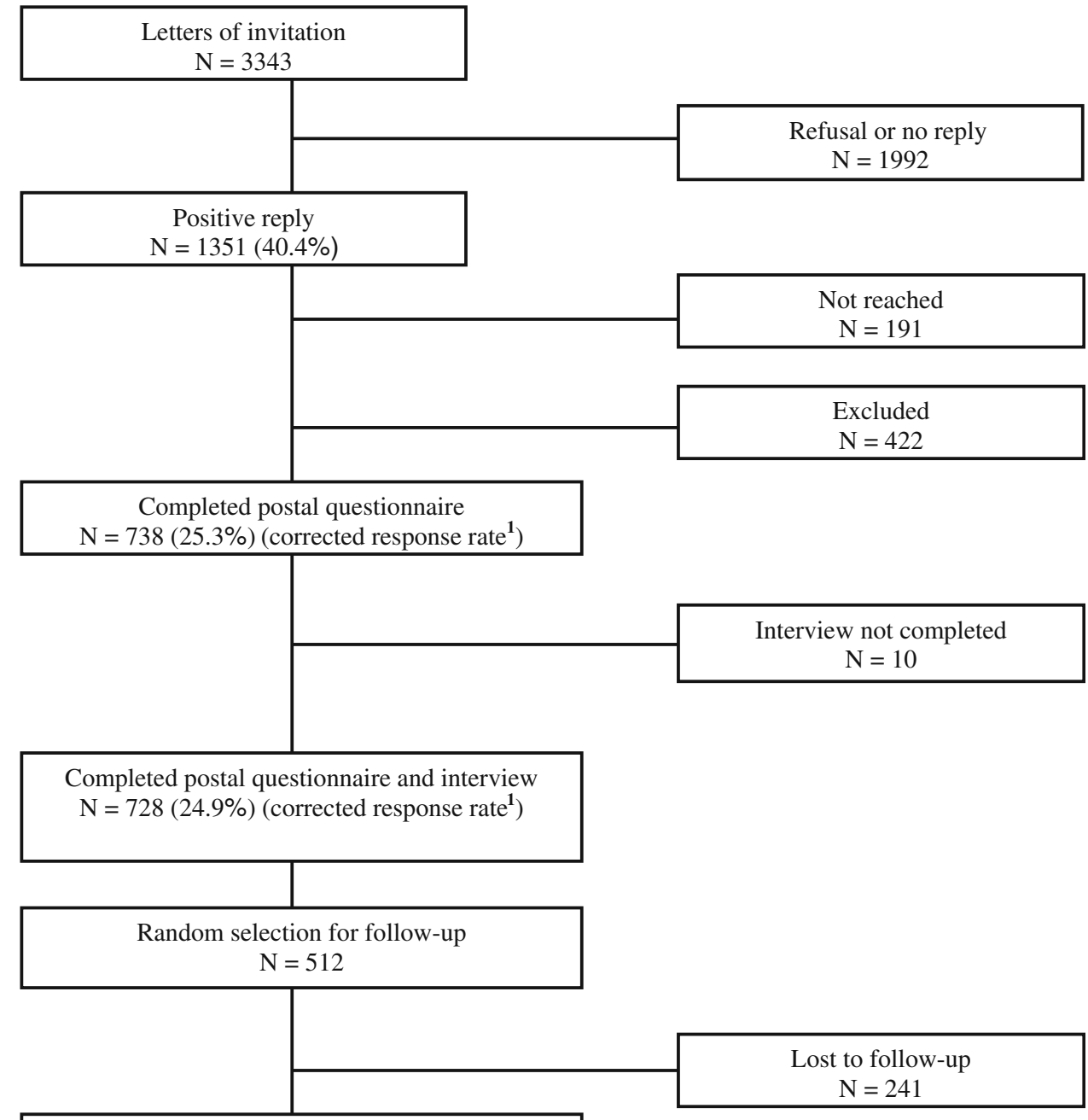

Follow-up interview at 3 months $271(52.9 \%)$

${ }^{1}$ The denominator of the corrected response rate was calculated by subtracting the number of excluded subjects from the total number of patients invited to participate $(3343-422=2921)$. 
Table 1 Patients' distribution per site across Canada

\begin{tabular}{llr}
\hline City & MPTF & $\%$ \\
\hline St. John's (NFLD) & Centre for Pain and Disability Management & 10.3 \\
Halifax & Pain Management Unit - Queen Elizabeth II Health Sciences Centre & 13.9 \\
Montreal & Pain Clinic of the Centre hospitalier de l'Université de Montréal & 13.9 \\
Montreal & Pain Centre of the McGill University Health Centre & 13.7 \\
London & St. Joseph's Health Care Interdisciplinary Pain Clinic & 13.9 \\
Winnipeg & Pain Management Centre, Health Sciences Centre & 101 \\
Calgary & Calgary Health Region Chronic Pain Centre & 100 \\
Vancouver & St. Paul's Hospital Pain Centre & 701 \\
\hline
\end{tabular}

MPTF $=$ multidisciplinary pain treatment facility; NFLD = Newfoundland

Table 2 Demographic characteristics of the study participants $(n=728)$

\begin{tabular}{|c|c|c|c|}
\hline \multicolumn{2}{|l|}{ Characteristics } & \multirow{2}{*}{$\frac{\%}{17.5}$} & \multirow{2}{*}{$\frac{n}{127}$} \\
\hline Age & $<40 \mathrm{yr}$ & & \\
\hline & $40-60 \mathrm{yr}$ & 58.6 & 427 \\
\hline & $>60 \mathrm{yr}$ & 23.9 & 174 \\
\hline Gender & Female & 60.6 & 441 \\
\hline \multirow[t]{3}{*}{ Education level } & Elementary school, high school & 46.3 & 336 \\
\hline & College-technical school & 35.4 & 257 \\
\hline & University & 18.3 & 133 \\
\hline \multirow[t]{4}{*}{ Employment status } & Employed (including students and homemakers) & 32.8 & 238 \\
\hline & Retired & 16.5 & 120 \\
\hline & Unable to work due to illness or disability & 41.9 & 304 \\
\hline & Otherwise not employed & 8.8 & 64 \\
\hline
\end{tabular}

because of their pain. The results obtained on the BDI-I (Table 4) revealed moderate to extremely severe levels of depression in half of the patients, while passive or active suicidal ideations were present in $34.6 \%$ of the subjects. Also, moderate to severe anxiety and anger levels were frequently observed (Table 4). Regarding health-related QoL, the patients reported significantly lower scores in all physical and mental domains of the SF-36v2 compared with the Canadian general population ${ }^{17}$ and patients with serious chronic medical conditions, including advanced coronary artery disease, complicated hypertension, or diabetes $^{18}$ (all $P$ values $\leq 0.001$ ) (Figure 2 ).

Current pain treatments and consultations with health-care providers

More than $80 \%$ of the patients $(83.9 \%)$ were taking prescription analgesic medication at the time of the study, with short-acting opioids being the most common type (Table 5). About one in ten patients was taking herbs/natural products (12.3\%) and/or cannabis (12.1\%) for pain relief (data not shown). Almost all patients (93.4\%) were using some kind of non-pharmacological pain treatments, including distraction $(60.5 \%)$, activity pacing $(51.4 \%)$, exercises $(48.8 \%)$, relaxation/breathing techniques $(46.1 \%)$, and massage $(27.3 \%)$. Since the onset of pain, patients reported having consulted an average of $7.4( \pm 3.6)$ different types of health care professionals (range 1-19) (Table 6).

Factors associated with severe pain

Multiple logistic regression analysis (Table 7) revealed that patients aged $>60 \mathrm{yr}$ were twice as likely to experience severe pain $(\geq 7 / 10)$ as their younger counterparts. Patients with frequent sleep problems were twice as likely to have severe pain as those who did not suffer sleep problems. A greater tendency to catastrophize in the face of pain, severe depressive symptoms, and higher anger levels were also significantly associated with intense pain.

Impact of a three-month wait time

As shown in Figure 1, more than half of the randomly selected patients (52.9\%) participated in the follow-up interview at three months. Statistical analysis in terms of age, sex, education level, and employment status revealed 
Table 3 Pain characteristics and pain-related interference

\begin{tabular}{|c|c|c|c|}
\hline & & $\%$ & $n$ \\
\hline \multirow[t]{5}{*}{ Cause of pain } & Trauma & 42.3 & 308 \\
\hline & Surgery & 9.2 & 67 \\
\hline & Illness & 18.7 & 136 \\
\hline & No precise event & 26.1 & 190 \\
\hline & Other & 3.7 & 27 \\
\hline \multirow[t]{4}{*}{ Pain duration } & $<2 \mathrm{yr}$ & 11.3 & 82 \\
\hline & $2-5 \mathrm{yr}$ & 41.7 & 304 \\
\hline & $6-10 \mathrm{yr}$ & 18.4 & 134 \\
\hline & $>10 \mathrm{yr}$ & 28.6 & 208 \\
\hline \multirow[t]{3}{*}{ Pain intensity $\geq 7 / 10$ (NRS) in the past 7 days } & At its usual level & 61.0 & 442 \\
\hline & At its worst level & 90.3 & 655 \\
\hline & At the present moment & 52.3 & 381 \\
\hline \multirow[t]{10}{*}{ Pain interference $\geq 7 / 10$ (BPI) in the past 7 days } & General activity & 66.5 & 442 \\
\hline & Mood & 59.6 & 433 \\
\hline & Walking ability & 55.6 & 404 \\
\hline & Normal work & 72.9 & 529 \\
\hline & Relation with others & 47.5 & 345 \\
\hline & Sleep & 67.8 & 493 \\
\hline & Enjoyment of life & 67.1 & 488 \\
\hline & Self-care & 33.8 & 245 \\
\hline & Recreational activities & 77.1 & 560 \\
\hline & Social activities & 63.9 & 464 \\
\hline \multirow[t]{4}{*}{ CPSI scores $=3$ (often) or 4 (almost always) } & Having trouble falling asleep because of pain & 71.3 & 514 \\
\hline & Need sleep medication to help to fall asleep & 61.1 & 441 \\
\hline & Awakened by pain during the night & 66.1 & 478 \\
\hline & Awakened by pain in the morning & 66.7 & 481 \\
\hline
\end{tabular}

$\mathrm{NRS}=$ numerical rating scale; BPI = Brief Pain Inventory; CPSI = Chronic Pain Sleep Inventory

Table 4 Psychological distress

Depression (BDI)

Depression levels

Normal (0-9)

Mild to moderate (10-18)

18.0

32.0

33.7

16.3

65.4

33.4

Passive thoughts

Active thoughts

None to mild (0-3)

Moderate (4-6)

Severe (7-10)

None to mild (0-3)

Moderate (4-6)

Severe (7-10)

Mean \pm SD: $30.0 \pm 12.3$

Moderate to severe (19-29)

1.29

$32.6 \quad 237$

$29.1 \quad 211$

$38.3 \quad 278$

$45.9 \quad 333$

$23.8 \quad 173$

$30.3 \quad 220$

Tendency to catastrophize $(\mathrm{PCS})(\min =0 ; \max =52)$

$\mathrm{SD}=$ standard deviation; NRS = numerical rating scale; BDI = Beck Depression Inventory; PCS = pain catastrophizing scale 


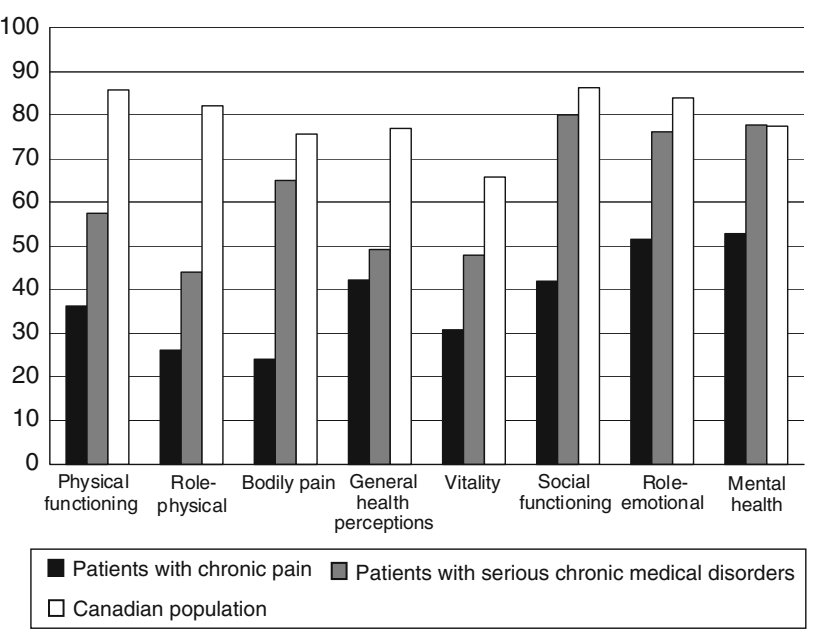

Fig. 2 Perceived health status according to the SF-36v2 subscales: using independent Student's $t$ tests, mean pain scores of the patients with chronic pain $(n=728)$ were compared with those of patients with serious chronic medical conditions $(n=144)^{18}$ and with the Canadian norms. ${ }^{13}$ (all $P \leq 0.001$ )

Table 5 Currently prescribed classes of medication in $>15 \%$ of the patients

\begin{tabular}{lll}
\hline Medication class & $\%$ & $n$ \\
\hline Short-acting opioids & 52.0 & 377 \\
Antidepressants & 40.9 & 296 \\
Anticonvulsants & 24.2 & 175 \\
NSAIDS - Coxibs & 23.4 & 169 \\
Long-acting opioids & 23.3 & 168 \\
Muscle relaxants & 17.9 & 128 \\
\hline
\end{tabular}

NSAIDs $=$ non-steroidal anti-inflammatory drugs

no significant differences between these participants ( $n=271)$ and those who completed only the initial assessment (457/728). Pain cause and duration were also comparable in the two groups (data not shown, all $P>0.05)$.

Table 8 displays small but statistically significant changes over a three-month period in the participants' condition. All measures of emotional distress (depression, anxiety, and anger) were significantly higher at that time, while inconsistent results were observed on the pain intensity measures.

\section{Discussion}

The STOP-PAIN Project is the first to document the burden of illness associated with chronic pain in individuals on waitlists of MPTFs across Canada. Our results highlight the severe impairment experienced by these patients. Almost all of the subjects experienced continuous pain, and close
Table 6 Types of health care professionals patients consulted for pain since its onset

\begin{tabular}{|c|c|c|}
\hline Health care disciplines & $\%$ & $n$ \\
\hline \multicolumn{3}{|l|}{ MEDICAL DISCIPLINES } \\
\hline Family practitioner & 96.7 & 704 \\
\hline Orthopedic surgeon & 46.6 & 339 \\
\hline Neurologist & 43.3 & 315 \\
\hline Physiatrist & 31.7 & 231 \\
\hline Anesthesiologist & 30.6 & 222 \\
\hline Neurosurgeon & 27.0 & 196 \\
\hline Dentist & 28.6 & 208 \\
\hline Psychiatrist & 31.0 & 226 \\
\hline Rheumatologist & 28.0 & 204 \\
\hline Gynecologist & 12.8 & 93 \\
\hline At least one other medical discipline & 10.4 & 76 \\
\hline \multicolumn{3}{|l|}{ PHYSICAL DISCIPLINES } \\
\hline Physiotherapist & 75.4 & 549 \\
\hline Massage therapist & 48.6 & 354 \\
\hline Chiropractor & 44.8 & 326 \\
\hline Occupational therapist & 29.7 & 216 \\
\hline \multicolumn{3}{|l|}{ COUNSELLING DISCIPLINES } \\
\hline Psychologist & 27.9 & 203 \\
\hline Nurse & 25.6 & 186 \\
\hline Social worker/counsellor & 15.1 & 110 \\
\hline Dietician/nutritionist & 0.5 & 4 \\
\hline \multicolumn{3}{|l|}{ ALTERNATIVE DISCIPLINES } \\
\hline Acupuncturist & 39.4 & 287 \\
\hline Naturopath & 10.7 & 78 \\
\hline Osteopath & 10.6 & 77 \\
\hline Homeopath & 8.0 & 58 \\
\hline Other alternative disciplines & 16.8 & 122 \\
\hline
\end{tabular}

to two-thirds of them rated their pain as severe. Also, the pain interfered substantially with activities in their daily lives. As previously observed in a similar population of Danish patients suffering with chronic pain, ${ }^{19}$ our study showed a major reduction in health-related QoL measured by the SF-36v2. The reduction in physical, psychological, and social functioning is remarkable in comparison with the Canadian population in general ${ }^{17}$ and patients suffering from other chronic diseases. ${ }^{18}$ However, these results are not overly surprising, considering that patients are referred to tertiary pain centres typically after all other health care resources have been exhausted and after patients have tried numerous treatments, including complementary and alternative medicine therapies.

The results documenting the association between pain and sleep are of special interest. More than one-half of the participants in the present study reported experiencing pain-related sleep disturbances on a regular basis. Patients who suffered from frequent sleep problems were at least 
Table 7 Factors associated with severe chronic pain - Logistic regression analyses were performed to identify variables that distinguished patients with severe pain $(\geq 7 / 10)$ from those who had pain of lesser intensity $(<7 / 10)$

\begin{tabular}{|c|c|c|c|c|c|c|}
\hline \multirow[t]{2}{*}{ Variables } & \multicolumn{3}{|c|}{ Univariate logistic regression } & \multicolumn{3}{|c|}{ Multivariate logistic regression } \\
\hline & $P$ value & Odds ratio & $95 \% \mathrm{CI}$ & $P$ value & Odds ratio & $95 \% \mathrm{CI}$ \\
\hline Age & 0.115 & 1.21 & $0.96-1.52$ & 0.002 & & \\
\hline$>60 \mathrm{yr} v s<40 \mathrm{yr}$ & & & & & 2.26 & $1.31-3.89$ \\
\hline$>60 \mathrm{yr} v s 40-60 \mathrm{yr}$ & & & & & 2.10 & $1.36-3.27$ \\
\hline Gender & 0.518 & 0.90 & $0.67-1.23$ & & & \\
\hline Education level & 0.005 & 0.75 & $0.62-0.92$ & & & \\
\hline \multirow{2}{*}{\multicolumn{7}{|c|}{$\begin{array}{l}\leq \text { high school } v s \text { college-technical school } \\
\leq \text { high school } v s \text { university }\end{array}$}} \\
\hline & & & & & & \\
\hline Employment status & 0.019 & 1.44 & $1.06-1.96$ & & & \\
\hline unable to work due to illness or disability $v s$ others & & & & & & \\
\hline Pain duration & 0.004 & 1.23 & $1.07-1.42$ & & & \\
\hline \multicolumn{7}{|l|}{$>10 \mathrm{yr} v s<2 \mathrm{yr}$} \\
\hline \multicolumn{7}{|l|}{$>10 \mathrm{yr} v s 2-5 \mathrm{yr}$} \\
\hline \multicolumn{7}{|l|}{$>10 \mathrm{yr} v s 6-10 \mathrm{yr}$} \\
\hline \multicolumn{7}{|c|}{ CPSI (often + almost always $v s$ almost never + sometimes) } \\
\hline Trouble falling asleep: & $<0.0001$ & 2.72 & 1.95-3.79 & & & \\
\hline Need sleep medication: & $<0.0001$ & 3.04 & $2.22-4.15$ & $<0.0001$ & 2.44 & $1.71-3.46$ \\
\hline Awakened by pain during the night: & $<0.0001$ & 2.36 & $1.72-3.24$ & & & \\
\hline Awakened by pain in the morning: & $<0.0001$ & 2.67 & $1.94-3.67$ & 0.0003 & 1.97 & $1.36-2.85$ \\
\hline Depression (BDI global score) & $<0.0001$ & 1.55 & $1.31-1.82$ & 0.003 & & \\
\hline \multicolumn{7}{|l|}{ Severe to extremely severe $v s$ normal } \\
\hline \multicolumn{7}{|l|}{ Severe to extremely severe $v s$ mild to moderate } \\
\hline Severe to extremely severe $v s$ moderate to severe & & & & & 2.61 & $1.35-5.05$ \\
\hline Anxiety & $<0.0001$ & 1.16 & $1.10-1.22$ & & & \\
\hline Anger & $<0.0001$ & 1.15 & $1.10-1.21$ & 0.016 & 1.09 & $1.02-1.16$ \\
\hline Tendency to catastrophize (PCS global score) & $<0.0001$ & 1.06 & $1.04-1.07$ & $<0.0001$ & 1.05 & $1.03-1.06$ \\
\hline
\end{tabular}

$\mathrm{CI}=$ confidence interval; CPSI = Chronic Pain Sleep Inventory; BDI = Beck Depression Inventory; PCS = pain catastrophizing scale

Table 8 Impact of a three-month wait time on pain intensity and psychological distress $(n=271)$. Paired Student's $t$ tests were used for comparisons of the scores obtained at the initial and follow-up interviews

\begin{tabular}{|c|c|c|c|c|}
\hline Variables & $\begin{array}{l}\text { Initial Interview } \\
\text { Mean } \pm \text { SD }\end{array}$ & $\begin{array}{l}\text { Follow-up Interview } \\
\text { Mean } \pm \text { SD }\end{array}$ & Mean difference & $P$ value \\
\hline \multicolumn{5}{|l|}{ Pain Intensity (NRS) } \\
\hline Usual level (0-10) & $6.7 \pm 1.9$ & $6.5 \pm 1.9$ & -0.2 & .021 \\
\hline Worst level (0-10) & $8.5 \pm 1.5$ & $8.3 \pm 1.7$ & -0.2 & .033 \\
\hline Present moment $(0-10)$ & $5.8 \pm 2.4$ & $6.5 \pm 2.1$ & 0.7 & $<.0001$ \\
\hline \multicolumn{5}{|l|}{ Psychological distress } \\
\hline Depression (BDI) (0-63) & $17.7 \pm 9.6$ & $18.8 \pm 10.1$ & 1.1 & .003 \\
\hline Anxiety (NRS) (0-10) & $4.8 \pm 2.9$ & $5.1 \pm 2.9$ & 0.3 & .024 \\
\hline Anger (NRS) (0-10) & $3.9 \pm 3.1$ & $4.2 \pm 3.0$ & 0.3 & .046 \\
\hline
\end{tabular}

$\mathrm{SD}=$ standard deviation; NRS $=$ numerical rating scale; BDI $=$ Beck Depression Inventory

twice as likely to report severe pain. The literature increasingly stresses the importance of paying more attention to the bi-directional relationship between pain and inadequate sleep, from both the diagnostic and the treatment points of view. ${ }^{20-24}$
With regard to emotional distress, the results on the BDI-I were consistent with those obtained on the SF-36v2 mental health subscale. Severe or extremely severe BDI scores were observed in a large number of patients. Anxiety and anger were also common in this population. 
Numerous epidemiological and clinical studies ${ }^{25-30}$ have documented the high prevalence of psychological comorbidities in patients with chronic pain, especially in those who experience significant limitations in their activities of daily living due to pain. For example, an international WHO survey of nearly 26,000 patients attending primary care facilities showed that chronic pain sufferers exhibited a four-fold increase in the odds of having an anxiety or depressive disorder relative to patients without persistent pain. ${ }^{26}$ Another recent review ${ }^{31}$ revealed that the risk of death by suicide was at least doubled in individuals suffering from chronic pain. In the present study, suicidal ideation was present in more than one-third of subjects, underscoring the need for clinicians to thoroughly assess depression. Our results revealed that the more depressed the patients were, the more likely they were to report severe pain. Older age, tendency to catastrophize, and anger were also significantly associated with intense pain.

In our study, statistically significant differences were observed in the patients' condition over a three-month period while they waited for their first appointment at an MPTF. However, it is debatable whether these results are clinically relevant. The significant differences observed on the measures of emotional distress (depression, anxiety, and anger) all pointed in the same direction, suggesting some sign of deterioration. However, the size of these differences was small. The same is true for the results obtained on the pain measures. Given that the median pain duration in our sample was $5.0 \mathrm{yr}$, perhaps a three-month period was too short to have a meaningful effect on the patients' condition in terms of pain severity and emotional distress. In two studies of patients being treated at an urban multidisciplinary pain centre in Denmark, no differences were seen after four months of waiting, ${ }^{32}$ but when patients waited six months, health-related QoL, anxiety, and depression scores deteriorated. ${ }^{33}$ These results are consistent with a systematic review ${ }^{34}$ that found patients experiencing a reduction in health-related QoL and psychological well-being while waiting six months from the time of referral to treatment for chronic pain. ${ }^{35}$

Like any other study, the present one has a certain number of limitations. It characterized only a small proportion of the chronic pain population, i.e., those who are waiting to be seen in a tertiary pain treatment centre. Therefore, they represent one subset of the population with chronic pain. The lack of firm diagnostic data on the study participants precluded analyses of subgroups of patients suffering from different pain syndromes. The study design did not allow inferences about causal relationships among the variables examined. Another limitation of the present study is the low response rate $(24.9 \%)$. Whether responders and non-responders differed in terms of their demographics or pain history was impossible to assess, since the latter group did not provide informed consent for collecting these data. However, considering they did not differ significantly from the groups of patients who completed the initial assessment in terms of age, sex, education level, employment status, and pain history (cause, duration) some generalizations can be viewed as possible from the sample who participated in the follow-up interview at three months. Nevertheless, some selection bias may remain among the responders. It is possible that severely affected patients may have been overrepresented in the individuals who completed the initial and/or follow-up interviews. Then again, they may have been underrepresented, since some patients may have been too sick, disabled, or distressed to answer the questionnaires.

Despite these shortcomings, our results have important clinical implications. In view of the severity and complexity of their condition, patients waiting for treatment in tertiary pain clinics present a unique set of challenges for assessment and treatment. Considering that Canadian MPTFs are unable to meet the clinical demand, both in terms of regional accessibility and reasonable wait times, ${ }^{4}$ it is clear that comprehensive and effective treatment strategies are needed. These should include earlier intervention in primary and secondary care settings to minimize suffering and psychological morbidity and, where possible, to prevent chronicity from developing. Factors, such as depression, sleep impairment, tendency to catastrophize, and anger, can all be modified and may require tailored interventions beyond simply treating pain. In conclusion, the poor bio-psycho-social profile observed in this sample of chronic pain patients who were referred to tertiary pain clinics should alert health care professionals and decision-makers to re-examine clinical priorities regarding resource allocation and to formulate better more cost-effective ways of delivering health care to individuals with chronic pain.

Acknowledgements The authors sincerely thank Mrs. Hélène Lanctôt, Research Coordinator of the STOP-PAIN Project, as well as the Research Nurses who were in charge of patient recruitment and data collection: Mrs. Mary Beth Booker, Linda Ferguson, Donna Hefferton, Denise Héroux, Louise Malysh, Paulette Nauss, Lynda Oliveros, Mala Ramu, Teralyne Wilson, Joanne Smith-Yong, and Myrna Yazer. Also, thanks are due to Mrs. Li Zhu and Annik Fortier, from the Biostatistics Service of the Montreal Heart Institute Coordinating Centre, who performed all the statistical analyses.

Funding sources This study was funded by the Canadian Institutes of Health Research/Rx\&D Collaborative Research Program (Grant No. DOP 68175) in partnership with Pfizer Canada Inc. Additional funds were obtained from three research networks of Fonds de la recherche en santé du Québec (FRSQ): the Oral Health Research Network, the Neurosciences and Mental Health Research Network, and the Rehabilitation Research Network. Mélanie Racine is a 
Canadian Institutes of Health Research Strategic Training Fellow in « Pain Research: From Molecules to Community » . Pfizer Canada Inc. did not influence the design, conduct, or reporting of the trial.

Competing interests None declared.

\section{References}

1. Moulin DE, Clark AJ, Speechley M, Morley-Forster PK. Chronic pain in Canada-prevalence, treatment, impact and the role of opioid analgesia. Pain Res Manag 2002; 7: 179-84.

2. Boulanger A, Clark AJ, Squire P, Cui E, Horbay GL. Chronic pain in Canada: have we improved our management of chronic noncancer pain? Pain Res Manag 2007; 12: 39-47.

3. IASP - Task Force on Guidelines for Desirable Characteristics for Pain Treatment Facilities. Desirable characteristics for pain treatment facilities. Available from: URL: http://www.iasp-pain. org/desirabl.html (accessed January 2010)

4. Peng $P$, Choiniere $M$, Dion D, et al. Challenges in accessing multidisciplinary pain treatment facilities in Canada. Can $\mathbf{J}$ Anesth 2007; 54: 977-84.

5. Veillette $Y$, Dion D, Altier N, Choiniere M. The treatment of chronic pain in Québec: a study of hospital-based services offered within anesthesia departments. Can J Anesth 2005; 52: 600-6.

6. Jensen MP, Karoly $P$. Self-report scales and procedures for assessing pain in adults. In: Turk DC, Melzack R, editors. Handbook of Pain Assessment. 2nd ed. New York: Guilford Press; 2001. p. 15-34.

7. Cleeland CS, Ryan KM. Pain assessment: global use of the Brief Pain Inventory. Ann Acad Med Singapore 1994; 23: 129-38.

8. Tyler EJ, Jensen MP, Engel JM, Schwartz L. The reliability and validity of pain interference measures in persons with cerebral palsy. Arch Phys Med Rehabil 2002; 83: 236-9.

9. Kosinski M, Janagap CC, Gajria K, Schein J. Psychometric testing and validation of the Chronic Pain Sleep Inventory. Clin Ther 2007; 29(Suppl): 2562-77.

10. Beck AT, Ward CH, Mendelson M, Mock J, Erbaugh J. An inventory for measuring depression. Arch Gen Psychiatry 1961; 4: 561-71.

11. Sullivan MJ, Bishop SR, Pivik J. The pain catastrophizing scale: development and validation. Psychol Assess 1995; 7: 524-32.

12. Sullivan MJ, Stanish W, Waite H, Sullivan M, Tripp DA. Catastrophizing, pain, and disability in patients with soft-tissue injuries. Pain 1998; 77: 253-60.

13. Ware JE Jr, Kosinski M, Dewey JE. How to Score Version 2 of the SF-36 Health Survey (Standard and Acute Forms), 2nd ed. Lincoln, RI: QualityMetric Incorporated - www.QualityMetric. com 2001

14. Guerriere DN, Ungar WJ, Corey M, et al. Evaluation of the ambulatory and home care record: aAgreement between selfreports and administrative data. Int J Technol Assess Health Care 2006; 22: 203-10.

15. Jensen MP, Smith DG, Ehde DM, Robinsin LR. Pain site and the effects of amputation pain: further clarification of the meaning of mild, moderate, and severe pain. Pain 2001; 91: 317-22.

16. Zelman DC, Dukes E, Brandenburg N, Bostrom A, Gore M. Identification of cut-points for mild, moderate and severe pain due to diabetic peripheral neuropathy. Pain 2005; 115: 29-36.
17. Hopman WM, Towheed T, Anastassiades T, et al. Canadian normative data for the SF-36 health survey. Canadian Multicentre Osteoporosis Study Research Group. CMAJ 2000; 163: 265-71.

18. McHorney CA, Ware JE Jr, Raczek AE. The MOS 36-Item ShortForm Health Survey (SF-36): II Psychometric and clinical tests of validity in measuring physical and mental health constructs. Med Care 1993; 31: 247-63.

19. Becker N, Bondegaard Thomsen A, Olsen AK, Sjogren P, Bech P, Eriksen J. Pain epidemiology and health related quality of life in chronic non-malignant pain patients referred to a Danish multidisciplinary pain center. Pain 1997; 73: 393-400.

20. Smith MT, Haythornthwaite JA. How do sleep disturbance and chronic pain inter-relate? Insights from the longitudinal and cognitive-behavioral clinical trials literature. Sleep Med Rev 2004; 8: 119-32.

21. Ohayon $M M$. Relationship between chronic painful physical condition and insomnia. J Psychiatr Res 2005; 39: 151-9.

22. Morphy H, Dunn KM, Lewis M, Boardman HF, Croft PR. Epidemiology of insomnia: a longitudinal study in a UK population. Sleep 2007; 30: 274-80.

23. Gupta A, Silman AJ, Ray D, et al. The role of psychosocial factors in predicting the onset of chronic widespread pain: results from a prospective population-based study. Rheumatology (Oxford) 2007; 46: 666-71.

24. Roehrs T, Roth T. Sleep and pain: interaction of two vital functions. Semin Neurol 2005; 25: 106-16.

25. Blyth FM, March LM, Brnabic AJ, Jorm LR, Williamson M, Cousins MJ. Chronic pain in Australia: a prevalence study. Pain 2001; 89: 127-34.

26. Gureje $O$, Von Korff $M$, Simon GE, Gater R. Persistent pain and well-being: a World Health Organization study in primary care. JAMA 1998; 280: 147-51.

27. Gureje $O$, Simon GE, Von Korff M. A cross-national study of the course of persistent pain in primary care. Pain 2001; 92: 195-200.

28. Arnow BA, Hunkeler EM, Blasey CM, et al. Comorbid depression, chronic pain, and disability in primary care. Psychosom Med 2006; 68: 262-8.

29. McWilliams LA, Cox BJ, Enns MW. Mood and anxiety disorders associated with chronic pain: an examination in a nationally representative sample. Pain 2003; 106: 127-33.

30. Ohayon MM, Schatzberg AF. Using chronic pain to predict depressive morbidity in the general population. Arch Gen Psychiatr 2003; 60: 39-47.

31. Tang NK, Crane $C$. Suicidality in chronic pain: a review of the prevalence, risk factors and psychological links. Psychol Med 2006; 36: 575-86.

32. Thomsen AB, Sorensen J, Sjogren P, Eriksen J. Chronic nonmalignant pain patients and health economic consequences. Eur $\mathbf{J}$ Pain 2002; 6: 341-52.

33. Becker N, Sjogren P, Bech P, Olsen AK, Eriksen J. Treatment outcome of chronic non-malignant pain patients managed in a Danish multidisciplinary pain centre compared to general practice: a randomized controlled trial. Pain 2000; 84: 203-11.

34. Lynch ME, Campbell F, Clark AJ, et al. A systematic review of the effect of waiting for treatment for chronic pain. Pain 2008; 136: $97-116$

35. Canadian Medical Association (CMA). Wait Time Alliance Report, fall 2007. Available from URL: http://www.waittime alliance.ca/images/Spring_2008/wta_report_card_eFINAL.pdf 2007 (accessed January 2010) 